\title{
Effects of acute ingestion of a multi-ingredient pre-workout supplement on lower body power and anaerobic sprint performance
}

\author{
AR Jagim", G Wright ${ }^{1}$, K Schultz $^{1}$, C St. Antoine ${ }^{1}$, MT Jones ${ }^{2}$, J M Oliver ${ }^{3}$ \\ From The Twelfth International Society of Sports Nutrition (ISSN) Conference and Expo \\ Austin, TX, USA. 11-13 June 2015
}

\section{Background}

Multi-ingredient pre-workout supplements (MIPS) are becoming popular dietary supplements among strength and power athletes. These products frequently include caffeine, creatine, beta-alanine, and branched-chain amino acids as the primary ingredients. When studied on an individual basis, several of these ingredients have been shown to increase muscular power following acute ingestion; however, little is known in regard to a synergistic effect when said ingredients are combined. The purpose of this study was to determine if short-term, MIPS ingestion influences muscular power and anaerobic sprint performance.

\section{Methods}

In a double-blind, randomized, and crossover design; 12 Division III male, football players $(18.8 \pm 1.2$ yrs; $180 \pm$ $12 \mathrm{~cm} ; 89.3 \pm 11 \mathrm{~kg} ; 13.6 \pm 4.9 \% \mathrm{BF}$ ) completed one baseline session and two subsequent testing sessions to determine the efficacy of acute ingestion of a MIPS. The initial baseline session consisted of body composition assessment and familiarization with the jump mat and non-motorized force treadmill. In testing Session 1, participants ingested either 1 serving of a commercially available MIPS (SUP) that contained $4 \mathrm{~g}$ of carbohydrates, $2 \mathrm{~g}$ of creatine hydrochloride, $3 \mathrm{~g}$ of beta-alanine, $1.5 \mathrm{~g}$ of betaine, $1 \mathrm{~g}$ of taurine, $600 \mathrm{mg}$ of N-acetyl L-Cysteine, 150mg of Alpha-Glyceryl Phoshporyl Choline, $6 \mathrm{~g}$ of citruline malate, $500 \mathrm{mg}$ of beet extract, $6 \mathrm{~g}$ of BCAA's, $1.5 \mathrm{~g}$ of L-tyrosine, $300 \mathrm{mg}$ of caffeine anhydrous, $50 \mathrm{mcg}$ of huperzine A and $5 \mathrm{mg}$ of BioPerine; or a placebo (PLA). Following a post-consumption

\footnotetext{
* Correspondence: ajagim@uwlax.edu

'Exercise \& Sport Science Department, University of Wisconsin - La Crosse, La Crosse, WI, 54603, USA

Full list of author information is available at the end of the article
}

30-minute waiting period, participants completed a warmup of 10 body weight exercises. Next, they completed a counter-movement vertical jump (CMVJ) test on a jump mat (Just Jump System, Probotics, AL, USA), which consisted of three attempts with the highest CMVJ being recorded for analysis and converted to power (W) using previously described methods [1]. Following the CMVJ, participants completed a 25 -second maximal effort sprint test on a non-motorized force treadmill with the resistance set at $18 \%$ of their bodyweight. Session 2 followed a week later in which participants repeated the testing protocol under the opposite treatment condition (SUP or PLA).

\section{Results}

Mean values for CMVJ power and treadmill performance work under each treatment are included in Table 1. There were no significant differences in lower body peak $(\mathrm{p}=0.584)$ or mean power $(\mathrm{p}=0.584)$ as determined by CMVJ. A significant increase in mean power was observed in the MIPS condition ( $\mathrm{p}=0.034)$ during the anaerobic sprint test. No significant differences were observed for any of the remaining anaerobic sprint performance variables.

\section{Conclusions}

Results suggest that acute ingestion of a MIPS 30 minutes pre-exercise has no impact on lower body muscular power, but improves mean power output during a maximal-effort anaerobic sprint. Based upon the results of the current study, ingesting a MIPS prior to a training session may improve anaerobic capacity during bouts of exercise lasting $<30$ seconds. 
Table 1

\begin{tabular}{lccc}
\hline \multicolumn{1}{c}{ Variable } & SUP & PLA & p value \\
\hline Peak Power $(W)$ & $1934 \pm 379$ & $1918 \pm 376$ & 0.719 \\
\hline Mean Power $(\mathrm{W})$ & $1468 \pm 304$ & $1397 \pm 257$ & $0.034^{*}$ \\
\hline Total Work $(\mathrm{m})$ & $107.1 \pm 4.8$ & $106.7 \pm 5.3$ & 0.384 \\
\hline CMVJ $(\mathrm{cm})$ & $65.2 \pm 7.0$ & $65.8 \pm 8$ & 0.584 \\
\hline Peak Power $(\mathrm{W})$ & $6470 \pm 895$ & $6513 \pm 898$ & 0.584 \\
\hline Mean Power $(\mathrm{W})$ & $3415 \pm 487$ & $3438 \pm 483$ & 0.584 \\
\hline
\end{tabular}

Values are presented as Mean \pm SD

*Significant difference between treatment conditions $(p<0.05)$.

\section{Authors' details}

'Exercise \& Sport Science Department, University of Wisconsin - La Crosse, La Crosse, WI, 54603, USA. ${ }^{2}$ Division of Health and Human Performance, George Mason University, Fairfax, VA, 22030, USA. ${ }^{3}$ Kinesiology Department, Texas Christian University, Fort Worth, TX, 76129, USA.

Published: 21 September 2015

\section{Reference}

1. Johnson DL, Bahamonde R: Power output estimate in university athletes. Journal of Strength and Conditioning Research 1996, 10(3):161-166.

doi:10.1186/1550-2783-12-S1-P49

Cite this article as: Jagim et al.: Effects of acute ingestion of a multiingredient pre-workout supplement on lower body power and anaerobic sprint performance. Journal of the International Society of Sports Nutrition 2015 12(Suppl 1):P49.

\section{Submit your next manuscript to BioMed Central} and take full advantage of:

- Convenient online submission

- Thorough peer review

- No space constraints or color figure charges

- Immediate publication on acceptance

- Inclusion in PubMed, CAS, Scopus and Google Scholar

- Research which is freely available for redistribution

Submit your manuscript at www.biomedcentral.com/submit 